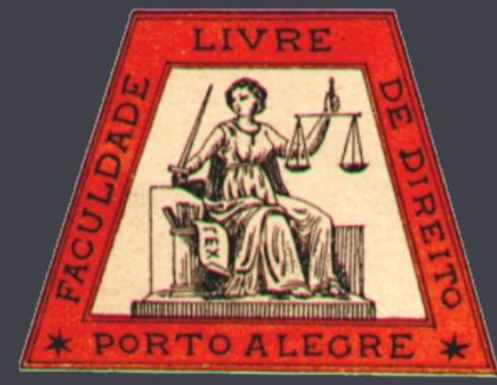

\title{
A crise da soberania e a era do constitucionalismo dos Direitos Humanos
}

Sovereignty crisis and the age of Human Rights constitutionalism

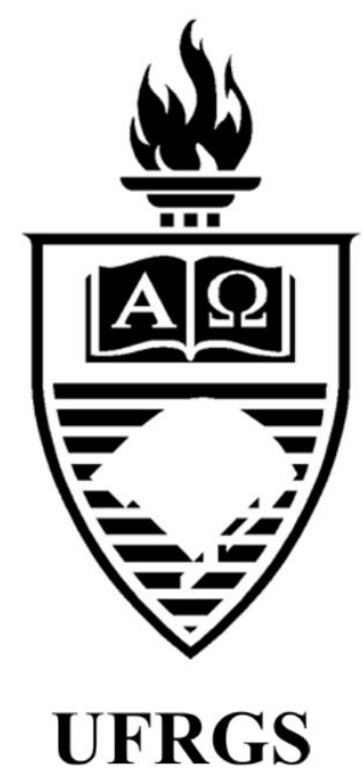

Helena Cristina Aguiar de Paula Vilela Universidade Federal da Paraíba 


\title{
A crise da soberania e a era do constitucionalismo dos Direitos Humanos
}

\author{
Sovereignty crisis and the age of Human Rights constitutionalism
}

\author{
Helena Cristina Aguiar de Paula Vilela*
}

\section{REFERÊNCIA}

VILELA, Helena Cristina Aguiar de Paula. A crise da soberania e a era do constitucionalismo dos Direitos Humanos. Revista da Faculdade de Direito da UFRGS, Porto Alegre, n. 34, p. 66-81, ago. 2016.

\section{RESUMO}

A Carta das Nações Unidas e a Declaração Universal dos Direitos Humanos, aliadas a outros documentos internacionais que se seguiram, definiram o marco do fim do modelo vestefaliano que predominou por três séculos e representou a consolidação do Estado Nacional soberano. A partir dessa premissa, o objetivo do presente artigo se constitui em desvendar em que medida o novo constitucionalismo inaugurado no pós-Guerra abalou a soberania estatal. Para que esse objetivo fosse alcançado, foi utilizada a pesquisa bibliográfica, realizada por meio de consulta em livros e artigos publicados, citando, em particular, os autores modernos, como Bodin, Hobbes, Rousseau e Kant que fundamentaram o poder político, além da doutrina estrangeira que ressaltou o novo modelo de constitucionalização de acordo com as práticas sociais, como Canotilho (2008), Zumbansen (2012), Müller (2014) e Petters (2012). Com base nestas teorias, vale destacar que com a implantação do direito internacional dos direitos humanos, um novo modelo de constitucionalização emergiu. O modelo de Estado soberano e constituição, que serviam de parâmetros para o estudo do constitucionalismo moderno, encontraram desafios que não deixaram a teoria tradicional intacta.

\section{PALAVRAS-CHAVE}

Constitucionalismo. Direitos Humanos. Soberania.

\section{ABSTRACT}

The United Nations Charter and the Universal Declaration of Human Rights, combined with other international documents that followed, defined the milestone of the end of the Westphalian model that prevailed for three centuries and represented the consolidation of the sovereign Nation State. From this premise, the objective of this article is to uncover to what extent the new constitutionalism that followed the post-war period impacted the State sovereignty. For this objective to be achieved, the bibliographic research was used, carried out through consultation in published books and articles, citing in particular modern authors such as Bodin, Hobbes, Rousseau and Kant, which justified political power, as well as foreign doctrine that emphasized the new constitutionalization model according to the social practices, such as Canotilho (2008), Zumbansen (2012), Muller (2014) and Petters (2012). Based on these theories, it is noteworthy that with the implementation of International Human Rights Law, a new constitutionalization model emerged. The model of sovereign State and Constitution, which served as parameters for the study of modern constitutionalism, found challenges that have not left the traditional theory intact.

\section{KEYWORDS}

Constitutionalism. Human Rights. Sovereignty.

\section{SUMÁRIO}

Introdução. 1. O fim do modelo vestefaliano? 2. A Declaração Universal dos Direitos Humanos e a exigência de um novo olhar sobre o Estado. 3. Constitucionalismo e a transnacionalidade dos direitos humanos: um novo paradigma. Conclusão. Referências.

\footnotetext{
* Mestranda em Ciências Jurídicas pela UFPB. Especialista em Direitos Humanos, Econômicos e Sociais pela UFPB em convênio com a ESMA/PB. Especialista em Direito Público pela UNIDERB. Delegada de Polícia Civil do Estado do Rio Grande do Norte.
} 


\section{INTRODUÇÃO}

Os Tratados de Paz de Vestefália do século XVII marcaram o fortalecimento dos Estados nacionais, após o fim da sangrenta Guerra dos Trinta Anos (1618 - 1648), no contexto da passagem das guerras religiosas, da descoberta das Índias e da centralização do poder absoluto nas mãos dos monarcas. A partir desse marco, o modelo de Estado soberano, consolidado na Europa continental, passou a ser exportado para o resto do mundo, que perdurou pela Idade Moderna e se manteve na contemporaneidade.

As Revoluções liberais que se seguiram na França e nos Estados Unidos, embora tenham indicado o início da Idade Contemporânea, pouco afetaram a soberania do Estado. Na realidade, essas revoluções impuseram limites através dos direitos declarados de não intervenção do Estado, as chamadas liberdades públicas, mas, nas relações externas, mantiveram o princípio do Estado soberano.

Esse modelo de Estado soberano manteve-se na comunidade de Estados até meados do século XX, sobretudo com o advento dos documentos internacionais que inauguraram uma nova era. Mais precisamente, a Carta da Organização das Nações Unidas (ONU) de 1945 e a Declaração Universal dos Direitos Humanos, aprovada pela Assembleia Geral em 1948, teriam marcado a derrocada do modelo vestefaliano de Estado, após seus trezentos anos de vigência. Isso se deu em razão de fatores, dentre os quais a internacionalização dos direitos humanos, que despertou a ideia de pessoa humana como sujeito de direito na ordem internacional, autônomo em relação ao Estado, transcendendo seu caráter de direitos protegidos somente no âmbito local.

Sendo assim, a autonomia do sujeito, aliada a fatores como a difusão da globalização econômica, criação de tribunais com jurisdição internacional, acordos comerciais com normatização própria que desafiavam os limites do estado, foi responsável pela emergência de um novo constitucionalismo. Nessa medida, a soberania do Estado antes absoluta passou a sofrer abalos, como será visto no decorrer deste trabalho.

Acrescenta-se a isto a noção de que o conceito tradicionalmente adotado para o constitucionalismo diz respeito à limitação ao poder do Estado que evoluiu com as Revoluções Burguesas do Século XVIII, mas sem alterar a soberania estatal considerada nas relações internacionais. Contudo, a partir de 1945, parece simplório continuar atrelando o constitucionalismo à limitação do Estado, tendo em vista os fatores que emergiram e alteraram o cenário em que foi construída a teoria do constitucionalismo moderno. Diante de tal constatação, importa indagar: Em que medida esse novo paradigma constitucional abalou a soberania dos Estados?

Com o intuito de desvendar esta indagação, o presente artigo parte do pressuposto de que o novo constitucionalismo precisa se adaptar à sociedade complexa que se apresenta, fazendo-se necessário o uso de uma metodologia interdisciplinar e aberta, para buscar respostas para o constitucionalismo que emerge além das fronteiras do Estado ou sem Estado. Essa nova visão deve ser esclarecida aos estudiosos do direito constitucional para tomada de consciência de que o constitucionalismo tradicional não explica com satisfação os fenômenos que emergem no mundo contemporâneo. Pois, a ascensão do direito internacional dos direitos humanos representou a mudança de paradigma, a qual seguiu se transformando no mundo global.

Para tanto, o caminho necessário a se percorrer neste artigo passa pelo estudo do modelo tradicional de Estado consolidado a partir dos Tratados de Vestefália. Após, será realizado um estudo crítico sobre um dos marcos desse novo paradigma, qual seja, a Declaração Universal dos Direitos Humanos de 1948, e sua 
influência sobre o suposto abalo à soberania Estatal, sob a perspectiva da transnacionalidade dos direitos humanos. Ao final, será possível identificar características do constitucionalismo emergente, que se apresenta aos estudiosos do direito nos dias de hoje.

Com base no que foi descrito acima, a pesquisa se embasará nas teorias que legitimaram o poder político do Estado nacional na Idade Moderna, precursores da noção de soberania. Além do fundador do direito internacional moderno, Francisco de Vitória, o teorizador da soberania como poder absoluto e perpétuo, Jean Bodin, além dos contratualistas Hobbes, Rousseau e Kant serão confrontados em suas distintas concepções de direito e Estado. Ainda, cabe ressaltar a contribuição dada por Ferrajoli no estudo da soberania moderna. No tocante ao estudo do constitucionalismo, destacam-se os autores estrangeiros que se dedicam ao campo do constitucionalismo global, como Canotilho (2008), Petters (2012) e Müller (2014), e transnacional, como Zumbansen (2012).

\section{O FIM DO MODELO VESTEFALIANO?}

O conceito de soberania como poder absoluto e perpétuo, inaugurado por Bodin, foi incorporado pelo Estado, em sua formação na Idade Moderna, e pelo ideário jusnaturalista que o legitimou. Baseado na soberania bodiniana e no grande Leviatã hobbesiano, o Estado nacional ganhou força com o declínio do poderio do Sacro Império Romano, algo que ficou ilustrado no momento da assinatura dos Tratados de Paz de Münster e Osnabrück, em que cada Estado nação foi considerado na assinatura da paz em Vestefália.

O modelo de Estado vestefaliano se sustentou por mais de três séculos até entrar em declínio. A razão de sua derrocada se deveu a fatores como a globalização judicial e econômica, que ascendeu no século XX, e às interações comerciais que se avolumaram e ganharam proporções além do Estado. Porém, foi decisiva a maneira que a pessoa humana passou a ser encarada no cenário internacional. $O$ Estado exclusivo representante do "supremo comando da vontade geral” (ROUSSEAU, 2015, L I, Cap. VI, p. 22) deu lugar à pessoa humana como sujeito de direito, que se insurge inclusive contra o próprio Estado, quando este violar seu direito.

Para Kelsen (1998, p. 152), a soberania dos Estados diz respeito à subordinação à ordem jurídica, seja à ordem estadual, seja desta em relação à ordem internacional. Por sua vez, Ferrajoli atenta para a distinção entre soberania interna e externa, afirmando que a soberania externa foi a que primeiro surgiu, com Grotius, mas, principalmente, com Francisco de Vitoria. "Segundo os historiadores do direito internacional, suas primeiras formulações remontam, junto com o direito internacional moderno e bem antes da soberania interna de Bodin e de Hobbes, aos teólogos espanhóis do século XVI" (FERRAJOLI, 2002, p. 5).

Vitoria teria fundado as bases do Direito internacional moderno sobre a legitimação da descoberta das Américas, em contraponto ao pressuposto privado dos descobrimentos. A partir de Vitoria, os filósofos jusnaturalistas passaram a teorizar a sociedade dos Estados soberanos, tratando da liberdade, soberania, guerra e escravidão. Porém, o modelo vitoriano de Estados absolutos, submetido ao direito das gentes persistiu ao longo do tempo, informando a cultura da comunidade internacional até a sua superação com a paz de Vestefália de 1648 (FERRAJOLI, 2002, p. 16).

$\mathrm{O}$ que marcou o pensamento vitoriano, posteriormente descontruído pelo modelo vestefaliano de Estado foram os limites impostos à soberania que defendera em sua obra. Vitoria construiu sua teoria do Estado, na obra Relección de la Potestad Civil, concebendo que o rei estava 
sujeito às leis que emanava, atribuindo limites ao poder soberano do monarca ${ }^{1}$.

Com o fim da Guerra dos Trinta Anos (1618-1648), os Tratados de Vestefália designaram o novo modelo de Estado, diferente do que se via até então na Europa. O resquício de intolerância entre católicos e protestantes dava o pano de fundo da Guerra pelo domínio da Europa continental. Através dos Tratados, o SacroImpério Romano-Germânico se dissipou, pois a cada príncipe alemão foram outorgados os direitos de soberania, com poder de declarar guerra e paz, e firmar alianças de acordo com seus interesses ${ }^{2}$.

Pelos Tratados de Vestefália, a Europa continental dividiu-se em Estados soberanos, fundamentando o pensamento político moderno sobre as bases do Estado nacional e da relação com os cidadãos. Esse pensamento foi inaugurado por Bodin, ao conceituar soberania como elemento indispensável à sociedade política, constituindo-se pela submissão à autoridade comum (BARROS, 2001, p. 227). Com Hobbes, a filosofia política jusnaturalista contribuiu à expressão maior à soberania absoluta dos Estados.

A formulação da personalidade artificial do Estado como fonte suprema da vontade e representação do outro (HOBBES, 1679, Cap. XVI, p. 257), que também deu suporte para fundamentação do direito associado ao Estado. Para Ferrajoli (2002, p. 20), a consequência desse pensamento repercutiu no "monopólio estatal da produção jurídica, da consequente unidade do ordenamento e da sua independência das fontes jurídicas extra ou supraestatais".

Segundo Hobbes, os Estados, da mesma forma que os homens no estado de natureza, encontram-se em guerra perpétua. Com isso, o estado civil surge como negação da natureza e legitima os Estados Soberanos a declararem guerra, com a missão de civilizar outros povos.

\footnotetext{
1 Conferir VITORIA, 2015, mais especificamente o capítulo 21.
}

Nesse mesmo sentido, Kant entendeu o estado de natureza como estado de guerra e que o direito se impõe pela força, diante da inexistência de um juiz para dirimir conflitos (KANT, 2005, p. 10). Nos termos de Kant, é necessário um contrato a ser realizado também entre os Estados, com o propósito de manter a paz entre eles e diante dos outros.

Essa proposta kantiana também está presente em Rawls que discorreu sobre o contrato em dois níveis, isto é, o primeiro contrato existente entre as pessoas e o segundo entre os Estados, de forma a estabelecer os fundamentos morais para as relações internacionais (NUSSBAUM, 2013, p. 283). Desse modo, os contratualistas consideraram o Estado como unidade básica e que as partes contratantes buscavam leis ou princípios voltados a esta forma fixa e fechada de organização. Esse olhar fixo e fechado para os Estados, sem enxergar o mundo, o lado de fora, as influências externas, torna o fundamento moral do segundo nível mais restrito e débil.

Se, por um lado, a passagem do estado de natureza para o estado civil representou, para alguns pensadores modernos, a formação absoluta dos Estados, em especial no plano externo, por outro, as revoluções que eclodiram no final do século XVIII buscaram limitar o poder dos Estados no plano interno, com vista a garantir as liberdades individuais.

As constituições concebidas no modo clássico, que visaram à limitação do poder do Estado, em seu formato originalmente liberal, proliferaram-se após 1789. Não há dúvidas que os Estados se transformaram e se depararam com limitações, principalmente no tocante às garantias e direitos humanos. A relação entre Estados e cidadãos mudou porque a soberania passou a ser limitada, impondo o tratamento entre sujeitos de

2 Para um estudo aprofundado, cf.: FRANCA FILHO (2006). 
direitos, em lugar da relação súdito e soberano (FERRAJOLI, 2002, p. 28).

As mudanças ocorridas com as revoluções liberais marcaram uma nova era: a contemporaneidade. Contudo, é precipitado dizer que o modelo vestefaliano aí declinou e a soberania foi limitada a tal ponto de ser possível falar em direitos titularizados pelos cidadãos independentemente da figura do Estado.

As Revoluções burguesas que marcaram o século XVIII e suas Declarações de Direito não revogaram a soberania dos Estados, pelo contrário, enfatizaram a sua legitimidade e o dever de obediência a suas emanações. Basta atentar para alguns artigos da Declaração Francesa ${ }^{3}$ para notar que os direitos naturais e inalienáveis não se apresentavam tão independente do Estado.

Para Douzinas (2009, p. 114), as declarações pregavam os direitos universais, mas, na verdade, ratificavam o poder ilimitado do Estado. Nota-se tal incongruência com a diferenciação que a Declaração anunciou, não por acaso, direitos do homem e do cidadão. O "homem" da Declaração não poderia ser universal naquele momento (e talvez nunca poderá), pois excluía deliberadamente as mulheres, escravos, estrangeiros, não cidadãos.

Além disso, embora pretendesse declarar direitos universais, havia aqueles reservados aos cidadãos, pela ordem soberana interna. Surgiu, então, um novo privilégio, que protegia uns e excluía outros: a cidadania. Assim, Douzinas (2009, p. 120) expôs o paradoxo da Declaração francesa, ao dizer que os homens podem até ter direitos inalienáveis, mas se não for cidadão, isto é, se não for amparado pelo Estado e suas leis, não terá direito algum.

A própria Declaração Universal dos Direitos Humanos de 1948, que se verá em seguida, foi fruto da negociação dos governos,

${ }^{3} \mathrm{O}$ Art. $3^{\circ}$. da Declaração Francesa ilustra tal argumento: "O princípio de toda a soberania reside essencialmente na assim como os tratados que se sucederam. Segundo Douzinas (2009, p. 129), “os direitos humanos são ainda predominantemente violados ou protegidos em âmbito local”. A própria ineficiência dos mecanismos de responsabilização dos Estados violadores de direitos humanos comprova que tais instrumentos foram criados para respeitar e garantir o escudo da soberania estatal.

Para contrapor os ideais liberais, a filosofia positivista em seu alto grau representada por Hegel ressuscitou o totalitarismo platônico, ao pregar a adoração ao estado, à história e à nação. De acordo com Popper (1974, p. 37-38), a doutrina hegeliana defendeu que "o Estado é tudo e, o indivíduo, nada, pois deve tudo ao Estado, tanto sua existência física como espiritual". Com essa visão, Hegel foi uma arma perigosa utilizada pela monarquia prussiana para forjar o Estado, representado como fim em si mesmo, não como mero instrumento para o verdadeiro fim: o ser humano (POPPER, op. cit.).

As forças totalitárias que ocuparam a Alemanha e Itália encontraram nesses países terreno fértil para a ascensão do idealismo e do autoritarismo. Além de serem países de forte tradição jurídica que reconheceram o Estado como única fonte do direito (FERRAJOLI, 2002, p. 32), havia o antagonismo de classe mais profundo nestes países (COLE, 1981, p. 83).

A soberania, porém, sobreviveu mesmo com a essência juspositivista. O primado da lei limitou o poder estatal, que passou a se sujeitar à lei, e fragilizou a soberania do Estado em detrimento de uma nova soberania decorrente do estado democrático de direito: a popular.

Com relação à soberania externa, o período correspondente a meados do século XIX até meados do século $\mathrm{XX}$ representou a mais voraz soberania absoluta. As conquistas coloniais contemporâneas, seguidas das duas guerras

Nação. Nenhum corpo, nenhum indivíduo pode exercer autoridade que dela não emane expressamente". 
mundiais, expuseram o estado de natureza hobbesiano em seu formato real e selvagem (FERRAJOLI, 2002, p. 34).

Os direitos dos homens enumerados nas Declarações de Direitos liberais agora compõem os textos das constituições. São emanados pelos Estados, compõe seu ordenamento jurídico e os obrigam ao mesmo tempo. Por ter o Estado como fonte, aplica-se somente aos cidadãos, gerando os privilégios e a discriminação, como relatado acima. Além disso, o direito internacional dos direitos humanos não poderia ser aplicado aos cidadãos, pois o direito enunciado nos tratados internacionais de direitos humanos não representava emanações estatais diretas, razão pela qual não eram enxergados. Assim, os Estados violadores dos direitos de seus cidadãos sequer cogitavam em ser punidos.

\section{A DECLARAÇÃO UNIVERSAL DOS DIREITOS HUMANOS E A EXIGÊNCIA DE UM NOVO OLHAR SOBRE O ESTADO}

$\mathrm{Na}$ Europa, uma nova guerra dos trinta anos eclodiu, entre 1914 e 1945, a qual se espalhou rapidamente pelos demais continentes. Os tratados de paz, dessa vez, desembocaram na formação da Organização das Nações Unidas (ONU), que elaborou a Declaração Universal dos Direitos Humanos de 1948 e, assim como Vestefália, inauguraram um paradigma de Estado, direito e poder.

Embora não tenha se apresentado como tratado internacional, a Declaração de 1948 vinculou os Estados, assumindo a fonte de costume internacional e elemento de interpretação (RAMOS, 2012, p. 27). Isso a tornou ainda mais influente, pois tratados são fruto de negociações entre governos, os quais tem liberdade para ratificar, fazer reservas e denunciar. No caso da Declaração Universal, aprovada pela Assembleia Geral da ONU, não foi sujeita à negociação, assinatura e ratificação, tampouco tem natureza sinalagmática, por isso é considerada fonte do direito internacional prescindindo a sua adesão pelos Estados.

Por essa razão, algumas disposições da Carta da ONU e da Declaração Universal afetaram sobremaneira a chamada soberania externa. A eliminação da "guerra justa" foi uma delas, tendo em vista que, a partir da sistemática da ONU, "só é admissível, não como justa, mas como legal, quando autorizada pelo Conselho de Segurança em determinadas situações previstas na Carta das Nações Unidas" (SORTO, 2013, p. 341). O uso da força seria, portanto, legítimo no caso de se mostrar necessário ao retorno ou manutenção da paz, em nome da autodeterminação e, de acordo com a Carta da ONU, também nas hipóteses de legítima defesa.

Mas, sobretudo, foi o tratamento dado pela Declaração aos direitos humanos o grande feito, no tocante à fragilização da soberania externa, pois os direitos deixaram de ser assegurados tão somente pelos Estados, com normas contidas em suas Constituições. Os direitos humanos adquiriram, a partir de então, status supranacional, consolidando o direito internacional dos direitos humanos.

A internacionalização dos direitos humanos derivou de uma manifestação do pósguerra, no século $\mathrm{XX}$, sendo, portanto, movimento recente em resposta aos seus horrores e à "Era Hitler" (PIOVESAN, 2010, p. 122). O ordenamento jurídico além dos Estados, que ao mesmo tempo os obriga, surge e abala a soberania moderna.

Órgãos, comitês, conselhos foram criados com mecanismos de fiscalização, e até de jurisdição, de modo a limitar a soberania estatal, tendo em vista que a proteção dos direitos humanos não se concebe mais exclusivamente apoiada nos Estados. A partir da internacionalização promovida especialmente pela Carta da ONU, o poder de responsabilização 
dos Estados coube agora, também, aos órgãos judiciais internacionais.

A soberania esvanece com a presença de normas imperativas (jus cogens) que não advém do próprio Estado, mas de uma ordem internacional. Nesse cenário, a pessoa humana ingressa no cenário internacional como sujeito de direito, algo impensado antes das guerras do início do século $\mathrm{XX}$, diante da supremacia do Estado soberano, único representante dos seus cidadãos na ordem externa.

A limitação à soberania estatal através do direito foi incluída nos intentos dos antecessores da Carta da ONU. A Magna Carta de 1215, Bill of Rights de 1689 e as Declarações de Direito do século XVIII não se revestiram do caráter universal como a Declaração de 1948, que elevaram a pessoa humana a titular de direitos na ordem internacional, como ser independente de Estado ou nacionalidade.

A grande contribuição para a mudança no paradigma constitucional se situou no ingresso na ordem jurídica internacional dos Tribunais contenciosos, criados para promover a apuração de violações a direitos humanos praticados por Estados. O constitucionalismo tradicional teve que encarar o surgimento de Tribunais regionais ou internacionais que funcionam, não somente como instância recursal independente das decisões internas, mas também como mecanismo de responsabilização do Estado. Tal responsabilização resulta da configuração do Estado como parte da comunidade internacional e signatária de tratados.

Embora tenha representado um avanço no tocante à prevenção e punição de casos de violação, tais Tribunais padecem de dois problemas, ambos relacionados diretamente com a soberania estatal. O primeiro problema refere-se

\footnotetext{
${ }^{4}$ O Decreto 678/92 que promulgou a Convenção Americana de Direitos Humanos (Pacto São José da Costa Rica) dispôs, em seu artigo $2^{\circ}$, in verbis: "Ao depositar a carta de adesão a esse ato internacional, em 25 de setembro de 1992, o Governo brasileiro fez a seguinte declaração interpretativa:
}

às barreiras impostas pelo Estado para que se faça valer as normas imperativas de direitos humanos previstas nos tratados.

Alguns Estados sequer permitem que órgãos de fiscalização adentrem o território nacional sem autorização para fiscalizar denúncia de violação aos direitos humanos. É possível citar o sistema interamericano de proteção aos direitos humanos, composto pela Comissão Interamericana e pela Corte Interamericana, como principais órgãos. O governo brasileiro fez constar declaração interpretativa à Convenção Americana, proibindo visitas ao Estado sem a autorização expressa ${ }^{4}$.

$\mathrm{O}$ segundo problema diz respeito ao fato de que as decisões de alguns Tribunais Internacionais carecem de força coercitiva. Tem ainda relação com a hipótese de não haver reconhecimento da jurisdição do tribunal, algo que depende exclusivamente do Estado, no exercício de sua soberania, em que predomina o voluntarismo estatal.

A sanção mais grave prevista pela Carta da OEA é aplicada no caso de ruptura do regime democrático do Estado, punida com a saída da Organização dos Estados Americanos. A Assembleia Geral, nos demais casos, deverá enviar relatórios, notas públicas, que irão causar "vexame internacional" ao Estado violador, se acaso o seu governante se importar com a opinião de órgãos internacionais de direitos humanos.

Fica evidente, portanto, que o Estado pode deixar de reconhecer a jurisdição de um tribunal internacional, escapando, assim, de sanções que porventura seriam a ele aplicadas. A própria Corte Internacional de Justiça, órgão jurisdicional da ONU, decidiu, na análise do Caso Timor Leste (1995), que seria necessário que o Estado infrator reconhecesse a jurisdição da Corte

"O Governo do Brasil entende que os arts. 43 e 48, alínea d , não incluem o direito automático de visitas e inspeções in loco da Comissão Interamericana de Direitos Humanos, as quais dependerão da anuência expressa do Estado"'. 
Internacional de Justiça, para que o processo fosse admitido. O caráter de obrigação erga omnes dos tratados de direitos humanos, portanto, não elimina a necessidade de reconhecimento para que a Corte processe e julgue o caso.

Além disso, Ferrajoli (2002, p. 42) observa que o princípio da soberania dos Estados continua sendo ressaltado pela Carta da ONU (art. 2, I e VII). Os Estados permanecem como negociadores em Convenções de direitos humanos e impondo sua cultura e seu regime de governo como barreira para efetivação de alguns dos direitos proclamados internacionalmente.

Encontra-se, ainda, sob o domínio dos Estados soberanos, a deliberação sobre a paz, ou de não declarar guerra, sendo esta a maior forma de manifestação de soberania. A ONU não consegue eficazmente conter a potência norteamericana, a qual possui poder de veto e de decisão perante o Conselho de Segurança. A soberania permaneceu latente e perdurará enquanto não existirem mecanismos internacionais com força suficiente para tornar efetivas suas decisões.

A ideia soberania interna dos modernos, atrelada à ausência de limites e de regras, conforme o conceito bodiniano de um poder sem restrições, declinou de vez com o advento do estado de direito democrático e constitucional. Atualmente, se sustenta a soberania popular, mas não do Estado, pois este é de direito e, portanto, não coexiste com um sistema sem regras.

Contudo, no tocante ao âmbito internacional pós-guerra, correspondente à soberania externa, os Estados mantêm sua soberania e a ONU preocupa-se em assegurá-la ao disciplinar que alguns assuntos estão reservados à

\footnotetext{
5 Domínio reservado refere-se à denominação dada por Trindade (2002) para designar a faculdade dos Estados de fazerem reservas a cláusulas dos tratados, impedindo, assim, interferências externas indesejadas.

6 Para uma definição de povo: "Na teoria política e constitucional, povo não é um conceito descritivo, mas claramente operacional. Não se trata de designar, com esse
}

competência interna de cada Estado. No entanto, vale dizer que o Estado figura, na maior parte dos casos, como principal violador dos direitos humanos e, nesse contexto, o domínio reservado ${ }^{5}$ serve para impedir que órgãos, instituídos pelo direito internacional, invadam a esfera estatal, chancelando, assim, as violações (TRINDADE, 2002, p. 420).

Para Nussbaum (2013, p. 375), “a declaração universal ofereceu somente uma base magra para a sociedade internacional, na medida em que ainda visa garantir os direitos humanos como assunto para uma ação individual de cada Estado, não para a comunidade internacional como um todo". De fato, potências mundiais utilizam-se dos direitos universalmente declarados de acordo com sua conveniência. Abstêm-se de se comprometerem em tratados internacionais, mas vestem a roupagem dos direitos humanos no momento em que apontam Estados violadores e a necessidade da "intervenção humanitária".

Aliás, a intervenção nos Estados sob o pretexto humanitário acaba disfarçando o real sentido de guerra contemporânea. Os Estados intervencionistas apresentam justificativas para invasão, mas, na verdade, há o cunho imperialista nessas ações, embora a Carta da ONU e a Carta da Organização dos Estados Americanos (à qual os Estados Unidos estão relacionados) tenham consagrado o princípio da não intervenção nas relações internacionais.

Os Estados criados modernamente para assegurar a vida das partes contratantes, em alguns casos, mostram-se uma ameaça de extermínio do seu próprio povo ${ }^{6}$. Pois, observa-se que as fronteiras dos Estados esmagaram grupos

termo, uma realidade definida e inconfundível da vida social, para efeito de classificação sociológica, por exemplo, mas sim de encontrar, no universo jurídicopolítico, um sujeito para a atribuição de certas prerrogativas e responsabilidades coletivas". (COMPARATO, 1997, p. 213) 
étnicos ou raciais inteiros por não reconhecerem a "nacionalidade" dos membros desses grupos. Essa proteção da nacionalidade caracteriza o modelo de Estado soberano, ainda bem difundido pela Europa continental e que, possivelmente, pode ser a causa de parte dos conflitos internos atuais.

\section{CONSTITUCIONALISMO E A TRANSNACIONALIDADE DOS DIREITOS HUMANOS: UM NOVO PARADIGMA}

Conforme explicitou Carbonell (2003, p. 9), o constitucionalismo contemporâneo se redefiniu nas últimas cinco décadas, principalmente após a Segunda Guerra Mundial, com a mudança no modelo de Estado constitucional, podendo-se até ser chamado de "(neo)constitucional"

ou

“(neo)constitucionalismos". O mundo se deparou com uma nova era geopolítica e o constitucionalismo tradicional não ficou intacto.

O debate, também, não se encerrou com os neoconstitucionalistas, embora tenham sido uma importante expressão do pensamento político durante a Guerra Fria, sobre a maneira em que Direito e Política interagem no desenvolvimento constitucional (BELZ, 1972, p. 663). Além dessa visão, as forças sociais e sistemas descentralizados fazem parte da nova visão referente ao processo de constitucionalização.

Embora a soberania estatal persista, não se refere mais ao modelo de Estado vestefaliano, com sua entidade privilegiada de organização política acompanhada de um conceito de soberania descontextualizada. O Estado passou a ser encarado uma organização política em meio a várias outras, que emanam influências sobre o ordenamento jurídico constitucional e não podem ser ignoradas.

A soberania pós-moderna, nesse sentido, desvinculou-se do Estado, principalmente pelas transformações nas relações internacionais, que agregaram espaços regionais e comunidades supranacionais organizadas, além das organizações não governamentais de alcance internacional, que transpassam as fronteiras fixas do Estado (BOLZAN DE MORAIS, 2011, p. 27).

Além de uma relativização do Estado, sob o ponto de vista do conceito de sociedade mundial, as relações humanas também se modificaram. O sujeito da sociedade civil do início da era do constitucionalismo moderno transformou-se no século XX em sujeito da sociedade de massas, tendo sido, ainda, substituído pelo sujeito cosmopolita de hoje (ZUMBANSEN, 2012, p. 33).

$\mathrm{Na}$ atualidade, a intensificação da interdependência entre os Estados distancia da ideia de isolamento e autossuficiência descrita nas teorias do contrato social que fundaram o Estado soberano e absoluto. Por mais que ainda persistam os Estados isolados, que tentam fechar suas fronteiras para as influências externas, não conseguem desacelerar a intensa integração econômica mundial.

Dessa forma, o sistema jurídico evoluiu para uma ordem plural, com o cenário de regulação e institucionalização em rápida mudança. É possível notar o surgimento de normas híbridas, ao mesmo tempo públicas e privadas, que não estão localizadas exclusivamente no campo nacional ou internacional. As fronteiras entre o que é jurídico e político tendem a desaparecer.

Nessa perspectiva, o constitucionalismo contemporâneo é posicionado como estrutura concebida a partir da inter-relação entre uma ordem política, jurídica, cultural e econômica, sob o ponto de vista institucional e normativo (ZUMBANSEN, 2012, p. 19). Por isso, exige-se, a partir de agora, que os pesquisadores lancem um olhar interdisciplinar ao constitucionalismo, considerando outras influências, principalmente aquelas advindas da sociedade. Além disso, apresenta-se cada vez mais latente a necessidade 
de um diálogo entre os diversos sistemas jurídicos, sob a perspectiva do direito constitucional além do Estado.

Com a quebra da associação entre Estado e Constituição, tornou-se possível conceber outros parâmetros para as normas constitucionais, dentre eles, a fim de exemplificação, normatizações de acordos comerciais, regulações relativas ao meio ambiente, à organização do trabalho. Por isso, impõe-se a necessidade da análise interdisciplinar, pois o estatuto e natureza da ordem não é exclusivamente jurídica.

Isso fica ilustrado ao se analisar a transnacionalidade dos direitos humanos. Alguns aspectos dos direitos humanos vão situá-los como transnacionais, tendo em vista que não se pode dizer que são exclusivamente direitos nacionais, assim como não se situam exclusivamente no cenário internacional. A construção teórica dos direitos humanos se baseia hoje no direito relacionado diretamente com a sociedade.

A implantação de um sistema internacional de proteção dos direitos humanos foi crucial para modificação do princípio do Estado soberano, por estabelecer que os Estados não são livres para tratar seus cidadãos em seus territórios (PETERS, 2012, p. 120). Além de integrarem o rol de direitos contidos nas constituições domésticas, os direitos humanos internacionais preveem mecanismos de limitação da ação do Estado em respeito à liberdade das pessoas.

Zumbansen (2012, p. 38-45) preocupase em esclarecer o termo "transnacional" a partir da dimensão espacial e conceitual. Espacial na medida em que demarca a extensão da normatividade além das fronteiras dos Estados, e conceitual porque a construção desses espaços envolve a atividade humana, comunicação e racionalidade.

Portanto, para se falar sobre a transnacionalidade de determinada instituição é necessário averiguar se os espaços em que a atividade se desenvolve atravessam as fronteiras do Estado, como também, se esses espaços são construídos a partir de alguma atividade humana. A lei transnacional, então, seria aquela que surge além do Estado de forma autônoma, mas mediando o direito nacional e o direito internacional.

O constitucionalismo qualificado na esfera transnacional como novo fenômeno emergiu historicamente no século $\mathrm{XX}$, mais especificamente após 1945, com a Carta da ONU, ou desde a década de 90, como resposta à globalização e à fragmentação do Direito Internacional (MÜLLER, 2014, P. 72). Na realidade, as teorias constitucionais tradicionais não dirimiram as questões que surgem, pois ainda estão atrelados a ordenamentos jurídicos homogêneos e Estados fixos. A fluidez, por outro lado, no quadro utilizado como parâmetro para o estudo do constitucionalismo remonta a exigência de uma nova metodologia que considere as diversas influências da sociedade mundial que se apresenta.

Ao entrar em cena, os direitos humanos internacionalmente considerados, a teoria do contrato social como fundamentação do regime de Estado perde o foco. A exigência do respeito aos direitos humanos, não somente dos direitos elaborados a partir do aparato legislativo interno, mas aqueles propostos na ordem internacional limitam sobremaneira a soberania nacional.

Todo esse processo de construção dos direitos humanos e dos denominados jus cogens serviram para desestabilizar o constitucionalismo moderno. Para atender à internacionalização e à globalização que marcaram o século XX, teve de ascender o constitucionalismo global, que deixa de considerar o Estado hegeliano e passa a enxergar os Estados como mais uma forma de organização política (CANOTILHO, 2008, p. 27)

Observa-se, entre os teóricos dos direitos humanos e de cidadania, a necessidade de se elencar uma espécie de "núcleo duro" contendo 
direitos a serem universalmente assegurados. Apesar de esse núcleo duro não deter o caráter coercitivo que se pretende, pode-se dizer que influenciam de alguma forma os Estados mais remotos, afinal, não há lugar no mundo em que as ideias de direitos humanos, dignidade, igualdade e termos justos de cooperação não residam (NUSSBAUM, 2013, p. 374).

Por outro lado, a análise do nível de proteção aos direitos humanos, fiscalização que se dá internacionalmente como forma de compelir os Estados a se comprometerem com os direitos essenciais, também tem seu lado perigoso. Tal análise fundamenta as chamadas intervenções humanitárias, que desconsideram, desta vez de forma irresponsável, a soberania estatal.

Daí vê-se a enorme incongruência de potências mundiais, que não são afetas à proteção dos direitos sociais e econômicos e se julgam mártires do mundo, intervirem militarmente em países que os ameaçam politicamente, sob o pretexto da intervenção humanitária. É o caso dos Estados Unidos, como observa Nussbaum (2013, p. 292): "fingem que seu sistema é fixo e completo, e resistem com todas as forças a qualquer demanda de que se modifiquem internamente, seja em questões de direitos humanos, de meio ambiente ou de políticas econômicas, seja em resposta à situação do resto do mundo". Os Estados Unidos utilizam-se do discurso da violação dos direitos humanos no exterior, mas desrespeitam o núcleo duro abertamente ao permitirem a pena de morte, por exemplo.

Considerando que o constitucionalismo sofre influências de todos os lados, seja pela globalização, seja pelo multiculturalismo, a metodologia do direito constitucional atual deve ser ampla e interdisciplinar. $\mathrm{O}$ movimento intelectual que gerou o constitucionalismo global enxerga acontecimentos nas relações internacionais como constitucionais. Nessa perspectiva, "a Constituição não é mais um texto de direito público que emana do Estado e se senta no topo da pirâmide da normatividade jurídica" 7 (ZUMBANSEN, 2012, p. 50). Dessa forma, a soberania dos Estados não deixa de ser considerada como parâmetro para um constitucionalismo doméstico, mas é insuficiente ao se considerar a humanidade em sua totalidade.

$\mathrm{Na}$ verdade, o constitucionalismo global não exige a união em um singular documento chamado "constituição mundial", mas devem ser dispersos em vários textos legais e na jurisprudência (PETERS, 2012, p. 119). É comum se observar nas decisões judiciais emanadas pelas Cortes dos Estados referências a normas estrangeiras e princípios aplicados a outros ordenamentos. Então, a Constituição e o direito emanado do Estado deixam de ser os parâmetros exclusivos para o estudo do constitucionalismo.

Nesse campo de visão, leva-se em conta que a ordem internacional acaba por se apropriar de princípios e valores relacionados ao constitucionalismo. $\mathrm{O}$ que compunha o constitucionalismo tradicional, ou seja, separação de poderes, proteção dos direitos fundamentais, limitação do Estado, dá espaço para os princípios de solidariedade e não uso da força nas relações internacionais.

\section{CONCLUSÃO}

O paradigma constitucional inaugurado a partir da Carta da ONU de 1945, seguida da Declaração Universal dos Direitos Humanos de 1948, aprovada pela Assembleia Geral, pôs fim ao modelo de Estado soberano que perdurou séculos, atravessando a Idade Moderna e Contemporânea quase que intacto. Embora a própria Carta da

\footnotetext{
${ }^{7}$ No original: "the constitution is no longer a "public law' text, emanating from state authority and sitting at the pinnacle of a pyramid of legal normativity."
} 
ONU tenha reconhecido o princípio de não intervenção nos assuntos internos dos Estados, os direitos humanos elencados na Declaração Universal alcançaram os países mais remotos, mobilizando Estados a seguirem garantias mínimas de proteção da pessoa humana.

Após vir à tona a barbárie causada pelo nazismo e pela Segunda Guerra, o direito internacional dos direitos humanos ganhou vida e trouxe consigo mecanismos de responsabilização dos Estados que abalaram sobremaneira a soberania intocável que detinha no plano internacional. A soberania representada pela possibilidade de declaração da "guerra justa" perdeu o sentido após o surgimento da ONU. Pois, a Carta de 1945 disciplinou as hipóteses de guerra lícita, mas aboliu a ideia de guerra justa.

Ainda assim, barreiras para a efetividade da justiça internacional demonstram que a soberania estatal prevalece no que se refere à responsabilização dos Estados por violações a normas imperativas. A atual "guerra justa" chama-se intervenção humanitária, chancelada pelas potências que compõem o Conselho de Segurança da ONU.

No âmbito interno, a soberania não é elemento do Estado de natureza ilimitada. Vem sendo submetida há séculos ao estado de direito. Contudo, no âmbito externo, a soberania estatal continua detentora do privilégio que interfere na efetividade dos direitos humanos e na solidariedade entre os povos.

Tal cenário, porém, sofre influências da emergente ordem jurídico pluralista, da transnacionalidade das instituições e da proliferação de organizações políticas e sociais que produzem regulamentações e normatizações próprias. A exclusividade do Estado e a hierarquia normativa da Constituição são revistas pelos estudiosos do direito, que precisam se reinventar e se utilizar de uma metodologia interdisciplinar e aberta, para acompanharem os trajetos da soberania que hoje parte da periferia e, também, dos grandes polos econômicos.

Resta evidente que a ideia de soberania estatal não se findou, apenas cedeu lugar ao surgimento de um constitucionalismo que considera a comunidade e a sociedade internacional, não restrita ao âmbito doméstico. Esse movimento que se iniciou com a internacionalização dos direitos humanos e se intensificou com a globalização econômica afetou consideravelmente a teoria constitucional e passou a exigir um novo olhar para o direito e para a sociedade que o reflete.

\section{REFERÊNCIAS}

BARROS, Alberto Ribeiro de. A teoria da soberania de Jean Bodin. São Paulo: Unimarco Editora, 2001.

BOLZAN DE MORAIS, José Luis. As crises do estado e da constituição e a transformação espaçotemporal dos direitos humanos. $2^{\mathrm{a}}$ edição. Porto Alegre: Livraria do Advogado, 2011.

BELZ, Herman. Changing conceptions of constitucionalism in the era of World War II and the Cold War. The journal of American history, vol. 59, num 3, dez. 1972. Disponível em: <http://doi.org/10.2307/1900662>. Acesso em: abr. 2015. 
CANOTILHO, J. J. Gomes. "Brancosos" e interconstitucionalidade: itinerários dos discursos sobre a historicidade constitucional. 2ª edição. Coimbra: Edições Almedina, 2008.

CARBONEL, Miguel (Org.). Neoconstitucionalismo(s). Madrid: Editorial Trotta, 2003.

COLE, G. Douglas Howard. Que é o socialismo? In: CRESPIGNY, A. e CRONIN, J. Ideologias políticas. Brasília: Ed. Universidade de Brasília, 1981.

COMPARATO, Fabio Konder. Variações sobre o conceito de povo no regime democrático. Estudos Avançados, vol. 11, n 31, 1997. Disponível em: <http://www.scielo.br/pdf/ea/v11n31/v11n31a13.pdf >. Acesso em: jun 2015.

DOUZINAS, Costa. O fim dos direitos humanos. São Leopoldo: Editora Unisino, 2009.

FRANCA FILHO, Marcílio Toscano. História e razão do paradigma vestefaliano. Anuário de Derecho constitucional latino-americano. 1445-1465. 2006.

FERRAJOLI, Luigi. A soberania no mundo moderno. São Paulo: Martins Fontes, 2002.

HEGEL, Georg W. Friedrich. Princípios da filosofia do direito. São Paulo: Martins Fontes, 1997.

HOBBES, Thomas. Leviathan. Public Domain, 1679.

KELSEN, Hans. Teoria pura do direito. $6^{\text {a }}$ ed. São Paulo: Martins Fontes, 1998.

KANT, Immanuel. Sobre la paz perpetua. $7^{\mathrm{a}}$ edicion. Madrid: Editorial Tecnos, 2005.

MÜLLER, T. Global constitucionalism in historical perspective: towards refined tools for internacional constitucional histories. Global constitucionalismo, vol. 3, mar, 2014. Disponível em: $<$ http://journals.cambridge.org/action/displayAbstract?fromPage=online\&aid=9168387\&fileId=S204 5381713000051>. Acesso em: abr 2015.

NUSSBAUM, Martha. Fronteiras da justiça: deficiência nacionalidade, pertencimento à espécie. São Paulo:Martins Fontes, 2013.

PETERS, Anne. Are we moving towards constitucionalization of the World Community? In: CASSESSE, Antonio. Realizing utopia: the furture of internacional law. Great Britain: Oxford University Press, 2012.

PIOVESAN, Flávia. Direitos Humanos e o Direito Constitucional Internacional. 11ª ed. São Paulo: Saraiva, 2010.

POPPER, Karl Raimund. A sociedade aberta e seus inimigos. Belo Horizonte: Ed. Itatiaia, 1974. Vol. 2.

RAMOS, Andre de Carvalho. Processo internacional dos direitos humanos: análise dos mecanismos de apuração de violações de direitos humanos e a implementação das decisões no Brasil. $2^{a}$ ed. São Paulo: Saraiva, 2012.

ROUSSEAU, Jean-Jacques. Do contrato social. Leme-SP: Edijur, 2015. 
SORTO, Fredys Orlando. O uso da força nas relações internacionais: da Paz Perpétua ao Terceiro Ausente. In: TOSI, Giuseppe (org). Norberto Bobbio: democracia, direitos humanos, guerra e paz. João Pessoa: Ed. Universitária da UFPB, 2013. Vol.2.

TRINDADE, Antônio Augusto Cançado. O domínio reservado dos estados na prática das Nações Unidas e das organizações regionais [1976]. In: TRINDADE, Antônio Augusto Cançado. $O$ direito internacional em um mundo em transformação. Rio de Janeiro: Renovar, 2002.

VITORIA, Francisco. Relección de la potestad civil. 1528. Pensamiento clásico español. Universidad de Navarra. Disponível em: <http://www.unav.edu/departamento/pensamientoclasico/francisco_de_vitoria> Acesso em: 26 dez. 2015.

ZUMBANSEN, Peer. Comparative, global and transnational constitucionalism: the emergence of a transnational legal-pluralist order. In: Global Constitucionalism. 2012.Disponível em: <http://digitalcommons.osgoode.yorku.ca/clpe/62>. Acesso em: mai. 2015.

Recebido em: 02/02/2016

Aceito em: 18/06/2016 
